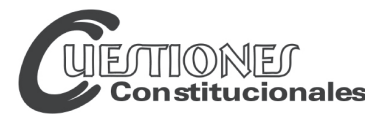

Revista Mexicana de Derecho Constitucional

Núm. 27, julio-diciembre 2012

\title{
LA LIBERTAD EN PARTE DEL PENSAMIENTO FILOSÓFICO CONSTITUCIONAL
}

\section{FREEDOM IN CONSTITUTIONAL PART OF PHILOSOPHICAL THOUGHT}

\section{Luis Raúl GONZÁLEZ PÉREZ*}

RESUMEN: Este trabajo expone algunas de las ideas relacionadas con el pensamiento filosófico constitucional en materia de libertad y su proyección jurídica. La tesis implica tener bajo consideración una visión amplia sobre la libertad y las consecuencias negativas del uso o ejercicio ilimitado de la libertad, así como exponer las opciones para adoptar una postura idónea de expresión acorde a las propuestas y alternativas que mayor beneficio otorguen a la sociedad. Sentar las bases para la discusión del tema de la libertad es parte esencial del propósito de este estudio.
ABSTRACT: This piece of work states some of the ideas that are related to constitutional philosophical thought on freedom and legal projection. The thesis involves having under consideration a wider view of the freedom and the negative consequences of its use or the exercise of unlimited freedom; whereas the options for adopting a suitable posture of expression, according to the proposals and alternatives, giving greater benefits to the society. Establishing the basis for discussion of a subject such as freedom is an essential part of the purpose of this study.
Palabras clave: libertad, libertad de expresión, limites a los derechos humanos, pensamiento liberal, pensamiento jurídico moderno, orden jurídico interno.
Descriptors: freedom, free speech, limits on human rights, liberal thinking, modern legal thought, the internal legal order. 
Podré no estar de acuerdo con lo que dices, pero defenderé hasta la muerte tu derecho de manifestarlo Voltaire (1694-1778)

\section{INTRODUCCIÓN}

La libertad constituye uno de los presupuestos del ser humano y con base en ella, pero al lado de la dignidad humana, se ha construido la esencia de los derechos de la persona. Las libertades públicas, ámbito de actuación del individuo oponible al actuar de las autoridades, han sido una conquista histórica que ha ayudado a la reivindicación del ser humano, razón por la cual resulta de especial importancia adentrarnos en los orígenes de su concepción así como en la evolución que ha experimentado mediante el pensamiento filosófico y político, para de esta manera poderla aplicar al pensamiento constitucional y en especial a los derechos de libertad. ${ }^{1}$

Ningún derecho puede ser de naturaleza absoluta, por lo que la tesis de Karl Popper resulta aplicable para demostrar las consecuencias negativas del uso ilimitado de la libertad, pues con ello se estaría trastocando el cúmulo de posibilidad que la propia sociedad requiere para el desarrollo pacífico individual y colectivo de sus miembros. ${ }^{2}$ En este sentido, Alberto Enegas Lynch y Carlota Jackisch, ${ }^{3}$ coinciden en que la libertad de expresión, pese a ser un derecho, debe ser ejercida mientras no lesione las posibilidades legítimas de acción de otras personas.

De ahí la importancia de que el Estado contemporáneo reconozca la individualidad del ser humano en la sociedad pero sin desconocer los límites en el actuar del gobierno y, para tal acción, debe partir de una base filosófica, ${ }^{4}$

1 El artículo 32.2 de la Convención Americana de Derechos Humanos, expresa que la posibilidad de hacer o abstenerse de cada persona está limitada por los derechos que asisten a los demás. La Convención dispone que ello deviene necesario en mérito de la seguridad de todos, del bien común y de una sociedad democrática.

2 Crf., Carpizo, Jorge, "La libertad de expresión frente a la no discriminación", Revista de la Facultad de Derecho de México, México, t. LIX, núm. 252, julio-diciembre de 2009, p. 11.

3 Límites al poder, los papeles antifederalistas, Buenos Aires, Lumiére, 2004, p. 61.

4 Cfr., Legaz y Lacambra, Luis, Filosofía del derecho, Michigan, Bosch, 1953, pp. 76 y ss. 
que le permita establecer políticas acordes a la tendencia protectora de la dignidad humana desde una perspectiva general que tenga en cuenta la transición del pensamiento clásico al moderno en materia de libertad.

En este artículo abordaremos la noción de libertad desde sus orígenes filosóficos con base en las nociones de dos grandes pensadores; después nos adentraremos en el estudio de la libertad desde el punto de vista de la filosofía política, en especial de la liberal para, finalmente, hacer referencia a la libertad desde el punto de vista jurídico y acudiendo a distinguidos pensadores. Queremos dejar sentado, desde ahora, que no pretendemos ser exhaustivos en la historia del pensamiento político sino que nuestra intención es más modesta y limitada a acudir al pensamiento de algunos pensadores con base en quienes podamos reconstruir la esencia de la libertad. ${ }^{5}$

\section{DOS PENSADORES DE LA LIBERTAD DESDE LA FILOSOFÍA}

El estudio de lo universal encuentra una nota trascendental cuando se ocupa del derecho o de las diferentes formas en que éste se manifiesta en la vida cotidiana.

La libertad en general ha sido una de las principales preocupaciones en el pensamiento filosófico clásico cuyos máximos exponentes, a partir de las características de este trabajo, son Aristóteles y Tomás Moro, bases del pensamiento filosófico liberal de las que más adelante parten John Locke, Emmanuel Kant y Alexis de Tocqueville, así como del pensamiento moderno y contemporáneo con ideas de John Stuart Mill, Norberto Bobbio, Robert Dahl, John Rawls y Luigi Ferrajoli.

Los autores en que basamos el análisis de la libertad en general, desarrollan aspectos que, a pesar de los siglos, no han perdido actualidad, sobre todo aquella reflexión que permite la actualización constante del contenido esencial de la libertad cuya estrecha relación con la posibilidad humana de hacer o abstenerse permite entender como es que ella funciona frente a la necesidad de los límites que su propio ejercicio armónico impone. ${ }^{6}$ Es importante resaltar que el pensamiento de los autores base para este estudio no es el único, las ideas que surgieron desde Sócrates hasta Dworkin,

5 Para un estudio profundo de la historia del pensamiento político se recomienda: Touchard, Jean, Historia de las ideas políticas, España, Tecnos, 2006.

6 Vecchio, Giorgio del, Filosofía del derecho, trad. de la 4a. ed., México, UTEHA, 1946, t. I, p. 394. 
pasando por Maquiavelo, Montesquieu Hobbes, Rousseau, Adam Smith, Robert Nozick son importantísimas y de suma relevancia, sin embargo el acotamiento estructural permite generalizar ideas e inclinarse al estudio más profundo de sólo algunos de ellos, conservando así, una sistematización adecuada respecto de la temática principal. ${ }^{7}$

Para comprender la idea de libertad y darle la protección teórica necesaria se debe transpolar al campo de la realidad, lo que implica la propia libertad en su concepción singular; y para ello nos apoyamos en el tratamiento que, a lo largo del tiempo, se ha dado a la prerrogativa esencial sobre la cual se constituye el Estado democrático.

Una de las concepciones más antiguas y, por lo tanto, de las más recurridas cuando de precedentes se trata, es la romana, con base en la cual se le ve como la facultad natural en virtud de la cual el hombre puede hacer lo que quiera, salvo que lo prohíba la fuerza o el derecho ${ }^{8}$. Se trata de una noción restringida, pues aunque resulta una de las más sólidas, encuentra en sí una limitación directa en la fuerza. Sin embargo, la concepción filosófica de libertad habla simple y llanamente de la capacidad natural del hombre de hacer, con lo cual queda claro que la libertad se ha considerado como intrínseca en la misma condición de ser humano cuyas limitantes no se encuentran consideradas en momento alguno, pues se contempla como la capacidad de obrar y decidir en la manera que se desee, sin que al respecto pueda considerarse como límite la obligación interna de actuar en la forma en que se ha decidido.

Desde esa perspectiva, la libertad se presenta como convicción individualizada que conlleva al ejercicio racional de los pensamientos, no arbitraria, no insensible de la naturaleza humana, sino como autodeterminación positiva de actuar de una u otra forma.

Podría advertirse una gran diferencia entre lo que es la libertad y la necesidad causal, pues puede considerarse al motivo como una condición previa a la existencia de la libertad, pero, si eso fuera correcto, entonces no habría un individuo enteramente libre, ya que estaría atado a las exigencias de las necesidades externas del hombre, lo cual es relativo y no absoluto.

7 La profundización en el pensamiento liberal puede estudiarse en Grondona, Mario, Los pensadores de la libertad, Buenos Aires, Editorial Sudamericana, 1986.

8 Montanelli, Indro, Historia de Roma, Barcelona, DeBolsillo, 2003, p. 284. 


\section{Aristóteles (384 a. C.-322 a. C.)}

Para el filósofo estagirita, la idea de libertad viene ligada a la esencia misma de ser humano. La libertad aristotélica reconoce a la persona la capacidad para decidir libremente y de manera racional frente a una amplia gama de opciones previamente ofrecidas, incluso, la facultad de actuar según la decisión que haya tomado. ${ }^{9}$

Si bien Aristóteles no contempló una definición concreta de libertad, lo cierto es que ofreció una idea básica de ella a través del zoon politikon (animal político). ${ }^{10}$

En su obra clásica intitulada La política, planteó que el hombre es político por naturaleza y, por ende, debe ser libre, es decir, no estar sometido a la potestad de alguien más, por lo que la persona sujeta a la esclavitud o cautiva no tiene esa naturaleza por estar impedido para participar en la vida social mediante la expresión de sus propias ideas y decisiones.

Al igual que la concepción romana, ${ }^{11}$ la idea de libertad de que parte Aristóteles es restringida, pues limita su ejercicio al hombre que no es esclavo o que no está cautivo, sin considerar que ello es circunstancial a la calidad de vida humana y ajena a la valoración que se da a la libertad como condición natural de todo hombre pues no debe olvidarse que nacemos libres $\mathrm{y}$, por lo tanto, capaces de relacionarnos y de vivir en sociedad, sin perder total autonomía con independencia de que, a la larga, seamos capaces de participar en la vida política de manera activa.

Aristóteles hace reflexionar sobre la condición mínima de libertad con la que debe contar toda persona para poder ser parte integrante de la sociedad, para poder desenvolverse con autonomía, ${ }^{12}$ pero no toma en cuenta un elemento fundamental que permite valorar la libertad en sentido intrínseco a la condición humana para tener en cuenta una de las condiciones que la vida en sociedad impone: la garantía de su ejercicio por parte del Estado.

La garantía de que hablamos también tiene presente aspectos morales y la concepción de la ética en cada ser humano, elementos que adquieren relevancia si recordamos que Aristóteles sostuvo que la ética sería nada si

\footnotetext{
9 Aristóteles, La política, trad. de Pallí Bonet, Julio, España, Bruger, 1974, pp. 78 y

10 Ibidem.

11 Cfr., Montanelli, Indro, Historia de roma..., cit., pp. 285 y ss.

12 Véase Aristóteles, La politica..., cit., p. 79.
} Ss. 
no tuviéramos en determinado momento la capacidad de ejercerla de manera racional y acorde a nuestros principios; decidiendo y deliberando. De esa manera, la forma de actuar de cada ser humano, según el autor en estudio, está ligada a su moralidad y a la rectitud de sus actos de ejecución.

Sin embargo, el ejercicio de la libertad no lleva implícita la facultad de actuar de la manera que se desee, pues aun cuando exista racionalidad el sujeto debe atender a factores o circunstancias que pueden advertirse como limitantes, que si bien no limitan a la libertad de manera absoluta, sí acotan el campo de acción de cada ser humano que debe ceder ante tales presupuestos.

Un individuo no puede, en ejercicio de sus libertades, tener mayores posibilidades, beneficios o prerrogativas que los demás seres humanos en su misma situación.

De ocurrir lo anterior, estaría abusando de sus derechos de libertad; cosa distinta es que, en ejercicio de la libertad misma, pueda optar por la búsqueda de los medios idóneos para ampliar los beneficios individuales, pero sin demérito de los colectivos.

Conforme a ello, la libertad queda extendida a la capacidad de elegir bajo propias circunstancias y determinaciones, pero nunca como capacidad absoluta de hacer lo que se quiera. Con eso logramos que la libertad personal se amplíe junto con la de los demás. De hecho, Aristóteles considera al abuso de la libertad como un atentado a los principios morales, dado que transgrede las libertades de los demás y el sujeto adopta una posición deshonesta al buscar beneficios por encima de sus semejantes al momento de elegir y ejecutar. ${ }^{13}$

\section{Tomás Moro (1478-1535)}

Este pensador opta por dar un tratamiento distinto al concepto de libertad y habla de "poder listo para obrar", mismo que refiere a la capacidad de elección y a la libertad de ejercer su voluntad sin coacción alguna. ${ }^{14}$

La autonomía de que habla Tomás Moro es conjunta al uso de la razón en la valoración de si se pretende llegar al bien a través de "la cultivación del espíritu y el desarrollo de las facultades intelectuales en el estudio de

13 Ibidem., p. 634.

14 Santibáñez, María, "El libre albedrío en La Vida es Sueño", Calderón 2000 homenaje a Kurt Reichenberger en su 80 cumpleaños, España, Kurt und Roswhita Reichenberger, 2002, vol. II, p. 624. 
las ciencias y de las letras". En pocas palabras, se trata de una guía para llegar a la felicidad. ${ }^{15}$

Lo anterior deviene completamente acorde con la tesis de Aristóteles solo que Tomás Moro la plantea desde un punto de vista colectivo, pues a su modo de ver las cosas "la utopía tiende esencialmente a satisfacer las necesidades del consumo público para que todos tengan tiempo de liberarse de las servidumbres físicas". ${ }^{16}$

$\mathrm{Al}$ respecto, sabe que la capacidad de elegir obedece indiscutiblemente a un elemento esencial del derecho de libertad, no obstante, esa elección debe ir acorde a cuestiones trascendentales que tengan un impacto positivo en la vida y el actuar del individuo ya que, de lo contrario, la libertad se estaría ejerciendo sólo de manera superflua.

La libertad y concretamente la de la voluntad o capacidad de elegir, aparecen como presupuesto y punto clave en la ética de Tomás Moro, por eso le otorga protección en la ley eterna y en la providencia de Dios, por ello adquiere amplitud y se considera, en la vida y en la práctica, como el libre ejercicio de las motivaciones internas que suelen presentarse, tales como la expresión de los deseos y el dominio pleno de la voluntad individual para concluir y llevar a cabo las acciones que puedan surgir del ejercicio mismo de la libertad.

En ese sentido, la libertad es considerada un don que se adquiere de forma divina y que realza su significado cuando se traduce en la facultad de elegir sin coacción si desea obrar o no. La libertad del hombre puede ser tan amplia que permite indistintamente la posibilidad de pensar, decidir y actuar sobre lo pensado, de poder expresar lo que se ha pensado, de actuar conforme a las propias convicciones pero teniendo en cuenta que su libertad no debe contravenir los principios de verdad y de justicia y, claro, respetando el o los derechos del prójimo.

Los peligros en el ejercicio de la libertad se reducen a que un individuo no sepa cómo deba usarla y que su ejercicio sea desmedido.

La esencia misma de la libertad reside en la idea de poder actuar conforme a lo que particularmente se desee y sin obstaculizar o perjudicar a los demás, los cuales se encuentran en plenas condiciones de ejercer sus derechos y de reclamar su protección.

15 Tomas Moro, Utopía, trad. de Claudio Roquette de Fonvielle, Buenos Aires, Sopena Argentina, 1941, p. 80.

16 Idem. 
Ahora, la libertad que propone Tomas Moro se complementa con el derecho a expresar las ideas, debido a la posibilidad de allegarse información y elegir qué es lo que se quiere saber y qué no. En efecto, la libertad está relacionada con la construcción de los pensamientos, pero esa relación no implica que el hombre pueda expresar sin limite su odio, desprecio o las burlas que considere, pues ello haría que la libertad aplicada al ámbito de la expresión verbal o corporal se torne ofensiva y contraria a una expresión armónica a la libertad de los demás.

De esa manera, la expresión de las ideas debe darse en forma respetuosa y con empatía. La imposición forzosa de ideas produce, de manera clara, actos soberbios que si los miramos a detalle, desembocan en el actuar que cualquier tiránico aplaudiría.

Santo Tomás remarca la idea de que si en algún momento el actuar humano perjudica de manera clara a las demás personas, entonces su derecho a la libertad debe limitarse, ya que la independencia en el pensamiento y en las ideas y posteriormente, en la expresión de las mismas: debe ser sin perjuicio de la dignidad humana, ${ }^{17}$ toda vez que el respeto a ésta mantiene la paz social.

En realidad, el tratamiento objetivo de las libertades parte del respeto que se tiene por los derechos de terceros, por la no transgresión ni vulneración que, para Santo Tomás, adquiere relevancia en el momento en el que se deja a salvo la libertad de creencia y de pensamiento. ${ }^{18}$

\section{LA LIBERTAD EN EL PENSAMIENTO LIBERAL}

La condición esencial para que las ideas o las teorías adquieran vigencia y logren el impacto deseado, es que partan de elementos convincentes y reales para lograr que los principios básicos de la idea o teoría, sean considerados como máximas de aplicación en la vida cotidiana y estén lejos de incurrir en planteamientos utópicos.

Con base en esa tendencia, los individuos tendrán la oportunidad de desenvolverse y tener una participación activa en la vida política con certeza de que el Estado respetará y garantizará en todo momento sus derechos. Veamos cuáles son los pensadores que en el plano moderno y contemporáneo estudian la libertad aplicada al servicio del individuo y su entorno.

${ }^{17}$ Ibidem, p. 112.

18 Idem. 
1. John Locke (1632-1707)

El filósofo Inglés de Wrington, ${ }^{19}$ es un contractualista moderno de corte iusnaturalista, cuyo pensamiento defiende la idea de un poder estadual limitado y pone a la libertad por encima de todo. A diferencia de Hobbes, quien planteaba que a través de un contrato social cada uno de los individuos cedería sus libertades en favor de un soberano que se encargaría de sacarlos del estado de naturaleza o de guerra de "todos contra todos", y que los dejaba sin la posibilidad de decidir, incluso, sobre su propia vida, ${ }^{20}$ Locke propone que se siga la idea del contrato, pero esta vez limitado por el respeto a los derechos de todos, pues el surgimiento del soberano derivó de la necesidad de solucionar conflictos en razón de la propiedad, no de decisión sobre la vida y libertad de los individuos.

Si bien John Locke tiene en consideración las teorías pronunciadas por Aristóteles y Tomás Moro, lo cierto es que con él surge la idea del poder como un límite negativo de la libertad cuando es impuesto de manera arbitraria o inconsciente de la condición natural de ser humano libre. A decir de este autor, quien tiene el poder absoluto es amo de los demás y en un esquema liberal, la intención es limitar al poder para proteger el ejercicio racional de la libertad.

Locke identifica a la libertad como un valor supremo que está por encima de cualquier otro derecho. Nos dice que no es legítimo sacrificar las libertades del individuo para otorgarle mayor poder al Estado, pues éste debe estar siempre limitado, así se desprende de la propia teoría de Montesquieu sobre la división de poderes.

Así, el pensamiento liberal de libertad se caracteriza por ser la base de la legitimación del poder y la condición de legitimidad del mismo en aras de preservar derechos. Con ese margen, el liberalismo ha tenido dos tendencias, aquella que se refiere al plano político y la que se ocupa de analizar el ámbito económico. No obstante, ambas ramas tienen su origen en la obra de John Locke y aún existe discusión sobre si pueden separarse o tienen que ir juntas.

19 Gran Enciclopedia del Mundo, 10a. ed., Barcelona, Duran, 1972, t. 12, pp. 12-70.

20 Véase Hobbes Thomas, Leviatán. o la materia, forma y poder de una república eclesiástica y civil, 2a. ed., trad. de Manual Sánchez Sarto, México, Fondo de Cultura Económica, 1980. 
El liberalismo político sostiene la necesidad de limitar al poder del Estado para garantizar derechos y libertades, mientras que el liberalismo económico sostiene al derecho a la propiedad privada por encima de todo. ${ }^{21}$

La visión de tolerancia en Locke es de naturaleza política y requiere que se reconozca a la libertad como factor indispensable para tener ideas y manifestarlas, así como el derecho a creer en lo que se quiera. De hecho, parte de ese iusnaturalismo antiguo se sostiene en la idea de que Dios creó a todos iguales y con dignidad de tener los mismos derechos. Incluso, cuando Locke habla del derecho de propiedad también menciona a la igualdad, a la dignidad y a la vida; su concepto de propiedad es más amplio que el de la tenencia de bienes. ${ }^{22}$

La obra de Locke lo potencializa como el padre del liberalismo moderno, ${ }^{23}$ entendido como el poder limitado por los derechos. Dice que hay un estado de naturaleza real y que los hombres en ese estado son iguales, libres, tienen propiedad, son independientes, viven en relativa paz y tienen que razonar en pro de sus semejantes y de sus relaciones.

El hombre naturalmente se sale de ese estado de naturaleza real cuando surge algún conflicto y necesita de alguien imparcial que decida si la conducta está bien o mal, actividad comúnmente otorgada al Estado. Locke opina que se sale de ese estado de naturaleza a través de dos contratos: a) el que crea a la sociedad y se llama pacto societatis, esto es, una Commonwealth, y b) el pacto de sumisión política para crear a la autoridad.

La existencia de esos dos pactos no implica renunciar a nuestros derechos naturales, los cuales se van a conservar como límites al poder del gobernante; nuestra libertad y propiedad se conserva y el único derecho al que vamos a renunciar será al de hacer justicia por propia mano, entendida por Locke como justicia privada. Va a existir una autoridad, una ley que nos limita el actuar, un juez que sentencia la conducta y un poder que

21 Cfr., Locke, John, Escritos sobre la tolerancia, edición de Luis Prieto Sanchís y Jerónimo Betegón Carrillo, Madrid, 1999, pp. 10 y ss.

22 Cfr., Salazar Ugarte, Pedro, La democracia constitucional. Una radiografía teórica, México, Fondo de Cultura Económica-UNAM, p. 78.

23 John Locke pone de manifiesto la idea de "Una libertad absoluta, una justa y verdadera libertad, una libertad e igualdad imparcial..." con lo que nos damos cuenta de las dimensiones que lleva implícita su idea que, en principio, siguiere una ampliación de las libertades en el culto religioso pero, al final del día, propugna por la ampliación de las libertades generales de todo individuo. Véase Locke, John, Escritos sobre la..., cit., p. 107. 
aplica las sentencias, es decir, la civilización del conflicto para pacificar la convivencia, saliendo así del estado natural y los derechos naturales para inspirar la creación de los derechos positivos. ${ }^{24}$

\section{Emmanuel Kant (1724-1804)}

El filósofo Alemán marcó la línea divisoria entre la teoría clásica y la moderna ${ }^{25}$ y además planteó la idea de la autonomía, vista como la capacidad de autorregulación moral. Al hablar de heteronomía, refiere que las reglas morales están dadas por algo externo que dice o sugiere como es que debe actuar o que es lo que debe o no hacer.

Para el pensamiento Kantiano las libertades y la autonomía deben prevalecer como signo principal de libertad. En ese sentido, al referirse a moral lo hace desde dos concepciones básicas, la primera, refiere una de tipo laica construida a partir de criterios racionales, donde la misma deviene analizada y decidida y, la segunda, enfatiza una moral de corte religioso a partir de lineamientos que sin más, dejan fuera todo tipo de cuestionamiento o razonamiento y únicamente atienden a lo establecido en la creencia eclesial.

No obstante, las ideas Kantianas se inclinan en favor de una moral laica donde el reto consiste en que el individuo piense por sí mismo y que gradualmente se ilustre para ser capaz de tener el valor de emanciparse de cualquier atadura y que el único faro en su vida sea la razón, incluso, afirma que las causas externas no influyen en la racionalidad del hombre, ni en la necesidad natural de sus acciones, pues la necesidad se satisface por impulsos naturales, mientras que de la razón y el conocimiento, no influenciado, se ejerce por la verdadera voluntad del sujeto, que en el terreno práctico se traduce en completa libertad. ${ }^{26}$

De esta manera, el imperativo categórico de Kant habla de una ley moral, pero se trata de una moralidad laica, descubierta a partir de la razón.

Tal imperativo parte de tres formulaciones que le dan sentido y que definitivamente lo extraen del plano teórico llevándolo a la praxis cotidiana. A saber:

24 Salazar Ugarte, Pedro, La democracia constitucional..., cit., p. 80.

25 Gran enciclopedia del mundo..., cit., t.11, p. 11.

${ }^{26}$ Crf., Kant, Emmanuel, La filosofía como sistema, primera introducción a la crítica del juicio, trad. de Pedro Von Haselberg, Buenos Aires, Facultad de Filosofía y Letras, 1948 , pp. 20-23. 
1. Actúa según una máxima que puedas creer que al mismo tiempo se torna ley universal;

2. Obra como si la máxima de tu acción debiera convertirse por tu voluntad en una ley universal de la naturaleza; y,

3. Obra o actúa de tal forma que uses a la humanidad tanto en tu persona como en la persona de cualquier otro siempre como un fin, nunca como un medio. ${ }^{27}$

La tercera formulación, reconoce al individuo gran valor pero tiene una idea de humanidad como conjunto de individuos, es por eso que parte de la idea de que no se utilice a los demás, de que no se utilice a la gente para un beneficio privado o personal, pues no debe utilizarse a cualquier individuo como un medio para lograr sus fines, siempre debe tratarse al individuo como un fin, es decir, tratar al individuo como si toda la humanidad recayera en esa persona, teniendo en cuenta que lo esencial es tratar al otro con respeto.

Kant es un liberal partícipe de la libertad negativa, entendida como la imposibilidad de que alguien pueda impedir hacer lo que la persona desea llevar a cabo, pues nadie lo obliga a hacer lo que no quiere, es decir, va a ser más libre entre más grande es el espacio en el cual pueda decidir qué hacer y llevar a cabo, puede hacer lo que quiera sin que alguien se lo impida, en resumidas cuentas, menor poder: mayor libertad, nadie impone decisiones ni le establece límites.

En otro plano, Kant se presenta como un liberal de la libertad positiva, misma que tiene que ver con la idea de que se es libre en la medida en que se es soberano; se es libre en la medida en que se es autónomo; y se es libre porque se impone sus propias normas, sus propios límites.

Lo anterior guarda relación con la teoría de John Stuart Mill que se analizará con posterioridad, pues ambos autores clasifican a la libertad para su estudio en positiva y negativa.

En la moral Kantiana uno debe actuar siempre con la naturaleza lícita de la finalidad, se trata de una moral de principios y no de contenidos, donde es importante ser juez sobre el propio actuar. El hombre como fin no tiene precio, sólo dignidad.

27 Cfr., Rivera Castro Fabiola, "El imperativo categórico en la fundamentación de la metafísica de las costumbres", Revista Digital Universitaria, México, vol. 5, núm. 11, 10 de diciembre de 1994. 
En su texto La paz perpetua de 1765, Kant está pensando en el contexto de la revolución francesa, para él son de suma importancia los derechos del hombre, es un iusnaturalista notoriamente preocupado por cómo debe organizarse un Estado, teniendo en cuenta que debe prevalecer el respeto a los derechos de cada uno de sus integrantes, por lo que propone como mejor opción a la República; Kant es el padre del republicanismo moderno.

La libertad de expresión en la idea republicana tiene especial importancia, sobre todo si se le analiza desde las tres perspectivas en que basa la esencia de la república moderna. A saber:

1. Ius civitatis, el republicanismo es una forma de gobierno que tiene como clave fundamental el principio de la división de poderes. La república siempre va a ser un Estado de leyes, porque existe un poder distinto al monarca que se encarga de la creación de las mismas. La república es totalmente opuesta al gobierno autoritario, toda la idea republicana está vaciada en la idea del ciudadano deliberativo, el ciudadano con virtud, el ciudadano que se compromete y participa;

2. Ius gentium, la república debe fundarse en una federación de Estados libres, cuyas leyes rijan la convivencia de los mismos;

3. Ius cosmopolita, una federación de Estado libres, con derechos universales, en donde todos sean ciudadanos del mundo, sean libres de estar en cualquier lugar del mundo en cualquier momento y que todos sean titulares del ius migrandi, un derecho de libertad cosmopolita que hace que todos los derechos sean de la universalidad..$^{28}$

Para Kant la relación en el mundo debe ser una Federación de estados libres (repúblicas) que además esté compuesta por ciudadanos libres.

Ahora bien, Kant habla del principio de publicidad, ${ }^{29}$ en él nos dice que cuando alguien ha hecho algo que no soporte la prueba de la publicidad, seguramente se trata de algo injusto o si se está pensando en hacer algo que no se desea que se sepa, es porque seguramente también lo es.

Ese principio esencialmente rescata la idea de actuar públicamente, entonces, si se hace algo se debe hacer bien y darlo a conocer, pues la libertad

${ }^{28}$ Cfr., Kant, Emmanuel, La filosofía como sistema ..., cit., p. 25.

${ }^{29}$ Idem. 
de los otros muchas veces depende también de la de uno mismo y al ocultar la publicidad de las cosas, también se está limitando el derecho de otros, como bien puede ser la libertad de expresión que es aquella que permite valuar o pronunciarse sobre el buen o mal funcionamiento del gobierno y su sociedad.

\section{Alexis de Tocqueville (1805-1859)}

Su obra más importante fue De la démocratie en Amérique publicada en 1835. En ella una de sus principales preocupaciones es la libertad y la conjuga con la igualdad, ${ }^{30}$ cuestión que representa uno de los retos básicos de la democracia.

Por un lado, la defensa de la libertad es lo que más debe importar y, por el otro, el principio de igualdad entre la sociedad. ${ }^{31}$

La libertad de mérito se basa en la concepción negativa propuesta por Kant, en tal sentido la llamada libertad negativa alude a la existencia de un campo de acción que no se puede ver limitado por poder alguno.

Al respecto, se prevé la existencia de varias dificultades, entre ellas la tiranía pues puede ser que cuando los poderes ejerzan algún tipo de acción no controlada: de manera automática limite la libertad, lo que representaría un gran riesgo para la democracia cuyos operadores jamás podrían aceptar el atentado.

La relación libertad-democracia representa un punto clave en la evolución de cualquier tipo de sociedad, pero Tocqueville logra hallar un problema en esta relación. Al referirse a libertad está preocupado por preservar los derechos de cada individuo y el campo de análisis se ocupa únicamente de la concepción individual de la persona mientras que, al hablar de democracia, hace alusión a la protección de la igualdad colectiva, esto es, dando preeminencia al rescate y conservación de derechos que comprenden a la sociedad en su conjunto. ${ }^{32}$

El interés encuentra sentido cuando vemos un Estado democrático que intenta que prevalezca la igualdad, pero paralelamente podría relegar la

30 Tocqueville, Alexis, La democracia en América, trad. de Marcelo Arroita-Jauregui, Madrid, Guadarrama, 1969, p. 11.

31 Ibidem, p. 328.

32 Ibidem, p. 329. 
libertad. En la actualidad, este problema se soluciona a través de la ponderación de derechos o de la armonización de los mismos.

En la concepción de Tocqueville la libertad juega un papel sumamente importante, pero sabe que dentro de la consolidación de la democracia se encuentra implicado el rescate de la igualdad colectiva, por lo que, si se trata de ser más justos probablemente lo que se consiga sea mayor justicia.

\section{LA LIBERTAD EN EL PENSAMIENTO JURÍDICO MODERNO-CONTEMPORÁNEO}

Hasta este momento del siglo XIX, podemos percatarnos que la idea de libertad va tomando un camino cada vez más complejo, desde su paso por la reflexión filosófica clásica hasta su análisis por grandes pensadores de la época moderna.

La aparición de las monarquías constitucionales o limitadas y el establecimiento del estado federal como opciones frente a un gobierno de corte absoluto o tiránico, hace que la posibilidad de hacer lo que se desee transite de simple actuación sin límite a un campo donde su ejercicio tiene que armonizarse con diversos postulados de la vida individual y estadual moderna.

De ahí el interés por plantear una idea de libertad susceptible de limitarse cuando ello no implique su entera marginación hacía el ámbito de confort que el propio Estado desee. Así, la evolución de la libertad ha marcado el camino en la construcción de los derechos, particularmente, el que toma a la libertad de expresión como límite al poder y que permite al individuo adentrarse y formar parte de las decisiones que se toman en la vida política y social del Estado, esto es, un reto fundamental para el pensamiento jurídico de los últimos años.

Las ideas hasta ahora analizadas, vienen acompañadas de propuestas y cada uno de los pensadores de los siglos XX y XXI pretenden darle realce a las libertades que hoy día deben considerarse como el eje estructural de todo Estado democrático de derecho.

La libertad de expresión, no sólo implica el poder expresarse de manera libre y sin amenazas o sanciones, lleva implícito todo un bagaje de libertades que van de la mano del derecho a buscar, recibir y difundir información; sin esos elementos, sería prácticamente imposible pensar en que la expresión pueda darse en forma previa, pues libertad de expresión significa idear, construir y materializar los razonamientos y las preocupaciones para supe- 
rar los retos que hoy nos ocupan. En este apartado expondré las tendencias que conjugan a la libertad de expresión con igualdad, poder y democracia.

Veamos cómo se presenta la libertad en la mente de los pensadores más representativos del liberalismo moderno y contemporáneo, sin soslayar el paso de una libertad simple a una de tipo acorde a los postulados de sistemas de gobierno limitados en cuyo interior se privilegia el valor de la democracia.

\section{John Stuart Mill (1806-1873)}

Para el clásico defensor de los derechos de libertad, principalmente de la libertad de expresión, ${ }^{33}$ la libertad es el derecho de cada hombre de "buscar su propio bien a su propia manera, en tanto que no se intente privar de sus bienes a otros, o frenar sus esfuerzos para obtenerla", ${ }^{34}$ de esa definición clasifica a las libertades esenciales de toda sociedad libre, sin importar la forma de gobierno, pues ante todo debe respetar la expresión y pensamiento. ${ }^{35}$

Respecto de la libertad de expresión y pensamiento, considera que no se puede concebir que un individuo tenga algún tipo de pensamiento si se encuentra ante la imposibilidad de expresarlo, a Stuart Mill le parece que la coexistencia entre pensamiento y expresión es fundamental, esto es, la expresión que lleva al pensamiento a dar un salto de un plano unidimensional al plano de la realidad.

En segundo lugar, le resulta difícil entender que la censura en la expresión de las ideas sea en forma previa a su manifestación expresa. En tal sentido, el error de la censura previa será exhibido y aceptado como verdad, y la verdad respecto a si debió o no de ser expresada quedará en un segundo plano y sin la atención del reflector social que pueda analizarlo.

En un tercer lugar, Stuart Mill considera que el hecho de que la autoridad asevere algo como cierto, no priva que las razones de su dicho sean susceptibles de análisis y debate, por el contrario, si la autoridad sabe que algo es verdadero pero no le resulta conveniente que se sepa y lo oculta, tal decisión es susceptible de ser contravenida, pues la autoridad no es

33 Stuart Mill, John, Sobre la libertad, trad. de Pablo Azcárate, Madrid, Alianza Editorial, 2000, pp. 116 y ss.

34 Ibidem, p. 22.

35 Idem. 
infalible, ${ }^{36}$ por lo que la libertad se considera el medio de protección del pueblo contra la tiranía estadual. ${ }^{37}$

Para el autor en estudio, resulta imposible poder separar el pensamiento de cada individuo de su expresión, si alguien tiene la capacidad de generar alguna idea mediante construcciones y abstracciones, para que las mismas adquieran significado alguno, necesitan darse a conocer, manifestarse, ser expresadas.

Sabemos que se trata de un campo de actuación en el que únicamente tiene intervención el individuo como sujeto de derechos, ya que, teniendo en cuenta que los pensamientos se generan en la conciencia de cada uno, tenemos entonces que la libertad de pensar, de razonar, de opinar, se gesta de manera interna y, la sociedad en general, no tiene intervención alguna en tal etapa de la libertad de expresión, ni el Estado obligación alguna de protegerla.

En el plano crítico, si bien el individuo continua siendo el único responsable de sus pensamientos, corresponde al gobernante cuidar que las ideas puedan expresarse sin menoscabo de las mismas, por lo que los límites legales deben a su vez privilegiar la plena libertad de idealización y construcción para que finalmente no se queden sólo en eso y pueda ser tutelada la posibilidad de manifestarla, lo que constituiría el efectivo cumplimiento de respeto a la libertad de expresión como un derecho inherente al hombre, toda vez que, como dice Stuart Mill, el pensamiento y la expresión resultan inseparables, de modo que el Estado deberá garantizarlos.

El ataque y destrucción de las fuentes de información resulta, en todo momento, una restricción indirecta a la libertad de expresión, pues, cada individuo pretende nutrirse tanto de información proveniente de fuentes públicas como de fuentes privadas y la destrucción de las mismas constituye un detrimento grave a la libertad de expresión, ya que resulta difícil pensar que un individuo pueda formular alguna idea o pensamiento crítico sin antes haber tenido acceso a alguna fuente de información, cualquiera que ésta sea. ${ }^{38}$

De hecho, Stuart Mill menciona que puede ocurrir que exista una persona que sostenga una idea tal y asegurar que es verdadera, toda vez que le trae un beneficio personal y junto a esta situación se presenta el resto del pueblo

\footnotetext{
${ }^{36}$ Idem.

${ }^{37}$ Ibidem, p. 5

${ }^{38}$ Ibidem, p.33.
} 
diciendo que la idea de aquel individuo es falsa, toda vez que no les trae beneficio alguno e incluso puede llegar a perjudicarlos.

Ante tal eventualidad, la solución que el autor plantea como cómoda para el gobernante sería la de silenciar a ese individuo, optando por el principio Habermasiano consistente en otorgar la mayor felicidad para el mayor número de personas, ${ }^{39}$ no obstante, lo que verdaderamente hace es socavar la libertad individual y, contrario a su deber y función de garante de los derechos, estaría limitándolos sólo por estar de acuerdo con la mayoría.

Si se limita la libertad de expresión y se deja una verdad como si se tratara de un error, a su vez, se le está limitando a los demás su derecho de conocer la verdad. ${ }^{40}$

En efecto, la limitación que ejerce el gobernante puede estar en concordancia con lo que el pueblo le está sugiriendo pero, silenciar a la minoría trae mayores consecuencias negativas, pues no se dan cuenta de que al limitar el derecho de uno, de manera automática se le está otorgando la facultad al gobernante de silenciar el de los demás y entonces la libertad de expresión queda subsumida a la voluntad estatal.

Por eso, el papel social es muy importante al momento de enfrentarse al gobernante, pues el planteamiento de límites debe quedar establecido del individuo hacia el gobernante, sin vulneración de la esfera de derechos, donde todos los individuos de manera colectiva sean capaces de hacer exigible su libertad de expresión a través de las instituciones establecidas para tal finalidad, constriñendo a la autoridad a actuar conforme al respeto y garantía de los derechos.

Se trata del primer autor que contempla a la libertad aplicada al campo de la expresión desde una perspectiva donde toca a la autoridad tomar consciencia de su papel falible, para asegurar que ello suele ser bastante frecuente, sobre todo cuando se tratan cuestiones tan importantes y trascendentes como son las relacionadas con derechos.

39 Sobre el materialismo que aborda Jürgen Habermas y el tratamiento de los intereses colectivos por encima de los intereses de cada individuo véase: Habermas, Jürgen, $L a$ reconstrucción del materialismo histórico, 5a. ed., Madrid, Taurus, 1992.

${ }^{40}$ Cfr., Carpizo, Enrique, Derechos fundamentales interpretación constitucional la corte y los derecho, México, Porrúa, 2009. 


\section{Norberto Bobbio (1909-2004)}

Con la revolución copernicana, los derechos se convierten en el fundamento del poder político y, por primera vez, se coloca en una situación prioritaria a los individuos y en una posición secundaria al Estado y su poder. Se trata de un giro en la concepción de las ideas. ${ }^{41}$

Este autor centra su atención en cómo la libertad de expresión, de reunión y asociación, logran un impacto positivo en cualquiera de las formas democráticas que se deseen adoptar, ${ }^{42}$ toda vez que una de las condiciones primarias para hablar de la existencia de un sistema democrático es precisamente la transparencia en el poder y en que la toma de decisiones colectivas tiene su origen en la participación de los individuos integrantes de cada Estado.

Bobbio sostiene que las reglas de la democracia, que él mismo llamó procedimientos universales, los cuales indirecta y directamente se encuentran relacionados con el ejercicio de la libertad, son seis:

1. Todos los ciudadanos mayores deben disfrutar de plenos derechos políticos, incluido el de expresar su opinión y elegir a quien la exprese por él.

2. El voto de todos los ciudadanos debe tener el mismo peso.

3. Todos los que disfrutan de los derechos políticos deben ser libres para poder votar según la propia opinión, formada lo más libremente posible, en una competición autónoma entre grupos políticos organizados en concurrencia entre ellos;.

4. Los ciudadanos deben también ser libres en el sentido de que deben ser puestos en la condición de elegir entre soluciones diversas.

5. Tanto para las elecciones como para las decisiones colectivas debe valer la regla de la mayoría numérica, y

6. Ninguna decisión tomada por la mayoría debe limitar el derecho de la minoría, particularmente el derecho de convertirse a su vez en mayoría en igualdad de condiciones. ${ }^{43}$

41 Bobbio, Norberto, Liberalismo y democracia, México, Fondo de Cultura Económica, 1996, p. 1 .

42 Ibidem, p. 8

43 Ventura, Adrián, Secreto Periodístico: Garantía Constitucional, México, Instituto de Investigaciones Jurídicas, 2010, p. 298. 
Como se ve, las cuatro primeras reglas y la sexta, no se podrían realizar sin un amplísimo respeto de la libertad de expresión, sobre todo en su dimensión política.

Por eso Bobbio encuentra algunos elementos que permiten acotar el alcance que habitualmente se le da a su definición de democracia como procedimental.

En efecto, para Bobbio ciertas libertades adquieren una dimensión sustancial.

Obsérvese que la quinta regla establece que las cuestiones deben quedar sujetas a la decisión de mayoría, con lo cual parece contradictorio sostener que hay un principio de libertad de expresión que está excluido del alcance de la mayoría parlamentaria. ${ }^{44}$

Sin embargo, la existencia de ese principio coincide con la sexta regla, porque la libertad de expresión está establecida como un derecho que permite dos cosas: el debate y la posibilidad de que la minoría se convierta en mayoría. Por eso, los derechos de libertad pueden ser vistos también como derechos contra la mayoría o límites contra la mayoría. ${ }^{45}$

\section{Robert Dahl}

En su obra sobresale su teoría de la democracia contemporánea norteamericana. Su libro Poliarquía, describe los sistemas políticos democráticos occidentales. ${ }^{46}$ Siguiendo la corriente del pensamiento democrático, el autor en estudio plantea una característica o institución importante dentro de la democracia poliárquica: la libertad de expresión, cuya afectación impide la participación efectiva de los individuos, haciendo que la agenda pública que recae en los integrantes de la nación sería una cuestión arbitraria del Estado.

Dahl opina que la libertad de expresión nunca es secundaria, pues si el individuo no tiene elementos básicos que le permitan expresarse de manera informada ${ }^{47}$ y con garantía del Estado, entonces jamás podrá tener conocimiento de las acciones y políticas gubernamentales y su capacidad

44 Idem.

45 Idem.

46 Cfr., García Jurado, Roberto, "Poliarquía y democracia", Estudios de filosofia, historia y letras, México, núm. 47, invierno 96-97, p. 40.

47 Ibidem, p. 54 
de influir y de tener alguna injerencia en las decisiones se vería reducida a su mínima expresión e incluso podría nulificarse.

De hecho, este autor sugiere que un Estado se puede considerar democrático si se ha ocupado de la protección de las libertades básicas y de los derechos humanos en su conjunto, pues la participación efectiva, la igualdad de voto ${ }^{48} \mathrm{y}$ el tener una comprensión política acorde a la situación actual, son fundamentales para lograr una adecuada injerencia en la agenda política del gobernante.

Al respecto, sugiere una lista de derechos que, en esencia, todo gobernante debe proteger:

1. Votar en la elección de representantes en elecciones libres y transparentes;

2. La posibilidad de competir para un cargo electivo;

3. La libertad de expresión;

4. Formar y participar en organizaciones políticas independientes (autonomía de asociarse);

5. Tener acceso a fuentes independientes de información; y

6. Tener los derechos a otras libertades y oportunidades que puedan ser necesarias para el funcionamiento efectivo de las instituciones políticas de una democracia de gran escala (ciudadanía inclusiva). ${ }^{49}$

Resulta sencillo determinar la magnitud que Dahl reconoce a la libertad de expresión. La mitad de los derechos y acciones que refiere se basan en una efectiva libertad de expresión.

La participación acorde y efectiva del ser humano en sociedad, deviene esencial para que el individuo tenga la información requerida y esté en condiciones de realizar lo que plantea en sus seis acciones de perspectiva política actual sin demérito de coincidir con los otros miembros del grupo al cual pertenece y lograr que tengan igual acceso a la información y puedan dar a conocer su particular punto de vista, toda vez que la igualdad política nace de la posibilidad de cualquier individuo de poder participar, ya sea directamente o a través de sus representantes, pero siempre tomando

48 Idem.

49 Dahl, Robert, La democracia, una guía para los ciudadanos, Buenos Aires, Taurus, 1999, p. 107. 
en cuenta la posibilidad de poder indagar al respecto, de poder discutir las temáticas correspondientes a sus intereses y de poder deliberar sobre lo que les resulta conveniente. Las limitaciones deben ser menores y racionales.

Es complicado pensar en la existencia de algún tipo de gobierno que garantice satisfactoriamente la protección de los derechos de libertad, pero el democrático es el que de alguna manera tiende a producir un menor daño ya que su intención es precisamente la protección de los mismos.

Claro está que se trata de una meta que pasará por varios infortunios, pero lo que si queda claro es que la protección de los derechos será la prioridad, no importando si se trata de derechos de mayorías o de minorías, la protección abarcará a todos.

Robert Dahl habla de la importancia que tiene no sólo la libertad que pueda tener un individuo en cuanto a la expresión de sus ideas, sino de la importancia que tiene para el gobierno y la sociedad que ese individuo esté informado, que tenga acceso a toda la información que él desee y que pueda y tenga la capacidad para poder discutirla y ser participe activo en la vida política.

Es ese sentido, la libertad de expresión adquiere mayor relevancia y se profundiza al considerarla como derecho de poder informarse y organizarse para la toma de decisiones con bases y sustentos que sirvan para la opinión crítica de cada uno de los individuos, opinión que, en ningún momento, el Estado podrá limitar en forma arbitraria, conservando así, la esencia de la igualdad política.

\section{John Rawls (1921-2002)}

Pensando en las sociedades modernas del siglo XX y XXI, escribió en el siglo XX, después de la segunda guerra mundial, que nuestras sociedades son plurales, que por lo regular no están de acuerdo con las decisiones y que su diversidad, la basan en una multiculturalidad muy amplia, tanto religiosa, como étnica, sexual y cultural.

Rawls opina que se debe lidiar con esas sociedades que son plurales, diversas y que se ven dañadas por la desigualdad social, por lo que la pluralidad se debe administrar, la diversidad debe fomentarse y la desigualdad social es 
un mal que debe superarse, ${ }^{50}$ al respecto se pregunta ¿cómo se puede lograr una sociedad justa, con instituciones justas y cómo es una sociedad justa?

La respuesta consiste en que una sociedad justa es aquella en que los bienes primarios se encuentran distribuidos de manera equitativa, entendiendo a los bienes primarios como todos aquellos bienes básicos que necesitamos satisfacer para tener una vida digna, ya que lo importante es garantizar a cada persona la libertad de ejercer su autonomía.

John Rawls dice que una persona es autónoma cuando puede planear su plan de vida e intentar llevarlo a cabo o cuando se le dan los elementos para planear su vida y llevarla a cabo, si eso sucede, entonces se está garantizando su autonomía y su vida digna.

La sociedad justa trata de que se cuente con los bienes primarios en condiciones de igualdad que le permitan llevar a cabo el plan de vida que pensaron o elegir autónomamente su proyecto de vida e intentar llevarlo a efecto. Si éste no se materializa, no quiere decir que la vida sea injusta, pues lo injusto sería que no se le otorguen los bienes primarios para intentarlo. ${ }^{51}$

El autor en estudio es un liberal heredero del pensamiento de Locke y de Kant, es individualista pues cree que los individuos deben ser los protagonistas de la vida social y cree que los poderes deben estar limitados en pro de dar mayor libertad a los derechos.

El pensamiento liberal-individualista va en contra del pensamiento utilitarista, mismo que tiene como máxima que lo que importa para lograr la justicia es lograr el mayor beneficio para el mayor número de personas, sacrificando los derechos de unos en aras de la felicidad de muchos. Rawls está del lado de los primeros y por eso nunca acepta que se pueda poner en riesgo el derecho de una persona por la felicidad de la mayoría.

Se trata de un liberal que propone tolerar al indeseable, por el simple hecho de ser titular de derechos. La obra de Rawls es liberal y en ella lo que importa son las personas con sus derechos por eso también rechaza el utilitarismo, el perfeccionismo y el intuicionismo.

Las razones de su rechazo al utilitarismo se basan en que pone al individuo en un segundo plano respecto del agregado social; y rechaza al perfeccionismo porque propone un estado moral de vida buena y trata de imponerlo. La autonomía entra en choque con el perfeccionismo, por eso no es aceptado

50 Cfr., Rawls, John, Liberalismo Político, trad. de Sergio René Madero Báez, México, Fondo de Cultura Económica, 1993, p. 40.

51 Ibidem, pp. 51-56. 
por los liberales. Rechaza también al intuicionismo porque a los principios morales se llega por medio de la razón, mientras que el intuicionismo dice que podemos llegar a esos principios por medio de intuiciones emocionales, irracionales e irreflexivas. El intuicionismo confunde la diferencia entre lo que está bien y lo que es justo.

Entonces, para determinar si una sociedad es justa o injusta se debe atender indiscutiblemente al criterio posicional de los derechos: si se encuentran en una misma base, entonces estamos en presencia de una sociedad justa; si están distribuidos, esto es, que se le otorguen mayores beneficios a algún individuo por encima de otro, se trata de una sociedad injusta. ${ }^{52}$

Ahora bien, Rawls habla de los derechos de libertad y los derechos de igualdad y elige a los de libertad. Existe un principio de diferencia que es la excepción al primer principio, que permite hacer salvedades y poner límites. El derecho de igualdad va a estar justificado si se generan desigualdades en derechos para favorecer a los más desfavorecidos, es decir, sólo se van a valer las excepciones a las libertades cuando se favorezca a los seres humanos en desgracia y se propicie la igualdad..$^{53}$

Este principio de igualdad debe entrar mediante pulsaciones del Estado para limitar las libertades de unos en favor de las libertades de otros, con el fin de generar igualdad, en tal contexto, las libertades estarían mal distribuidas en la medida en la que se presente mayor desigualdad social. Rawls cree que la libertad es el principio más importante y la igualdad sirve para controlar las libertades. ${ }^{54}$

El liberalismo igualitario plantea la idea de que los individuos son sujetos de derechos independientemente del grupo social al que pertenecen. Pero, en el discurso liberal igualitario no todo se vale, hay límites, no se puede invadir la identidad liberal de otros y no se puede hacer uso desmedido de los bienes compartidos para lograr una finalidad individual y dejar sin las mismas posibilidades a los demás.

Dentro de los límites tenemos que debe tratarse de un Estado neutro, que sea tolerante, pero que también sepa limitar lo intolerante y permitir que los individuos profesen la religión que quieran, que tengan la sexualidad o preferencia sexual que puedan y deseen, que vistan como quieran, en

52 Ibidem, p.40.

53 Ibidem, p. 98.

54 Ibidem, p. 256. 
pocas palabras, proteger y apoyar la libertad de expresión como elemento fundamental de las libertades de los individuos.

\section{Luigi Ferrajoli}

Para este filósofo del derecho, ${ }^{55}$ la esencia de la democracia reside en el contenido de los actos del Poder Legislativo y es precisamente allí donde surge cierta vinculatoriedad entre poderes y derechos.

Comenta que el Legislativo se encuentra limitado por un coto vedado ${ }^{56}$ que no debe contravenirse so pena de conculcar derechos. Ese límite frena cualquier tipo de actividad legislativa tendente a socavar alguno de los derechos consagrados a favor de los seres humanos. ${ }^{57}$

Así, considera que el legislativo se convierte en el primer protector de los derechos, toda vez que en él reside la responsabilidad de legislar acorde y conforme a la protección de los derechos humanos. En tal sentido, corresponde al legislador sancionar las conductas que propicien el detrimento y menoscabo de los derechos de los individuos y en él también recae la responsabilidad de dar amplitud a los mismos.

Al respecto, Ferrajoli remarca que ninguna mayoría puede violar derechos por ser considerada mayoría, ${ }^{58}$ esto es, la existencia de un legislativo garante crea la certidumbre de que los derechos serán reconocidos y respetados y que incluso siendo minorías, los derechos se respetarán en igual medida.

La libertad de expresión constituye un derecho de libertad que el Estado, por conducto del legislativo está obligado a proteger y a desarrollar, esto es, la creación de normas que se ocupen de otorgar la mayor protección posible para que no se vulnere tal derecho y, en segundo, cuando se ha vulnerado éste, crear las sanciones y medidas adecuadas que propicien la conciencia y el respeto a los derechos de libertad.

En el mismo sentido, el papel protector del legislativo comienza cuando en las mismas normas queda establecida la importancia de protección de los derechos de libertad, en las cuales se conmine al Estado a dar acceso a la información que el particular requiera y brinde la oportunidad de difundirla,

55 Ferrajoli, Luigi, Teoría de la democracia, dos perspectivas comparadas, México, Instituto Federal Electoral, 2001, p. 80.

56 La adopción del término formulado por Ernesto Garzón Valdés es propia.

57 Ibidem, pp. 16- 20.

58 Ibidem, p. 21. 
ya que si un individuo la conoce, todos tienen derecho de conocerla y podrán asimilarla y en su oportunidad, ejercer su libertad de expresarla conforme a sus intereses personales, salvo que se trate de información reservada.

Como puede observarse, Ferrajoli propone que la garantía de las libertades por parte del Estado es responsabilidad del legislativo, quien en todo momento debe otorgar leyes que reconozcan el ejercicio efectivo de la libertad de expresión.

\section{CONCLUSIONES}

La historia de las libertades revela un indiscutible tratamiento conforme a los nuevos acontecimientos. La adaptabilidad de los derechos al modo de vida en el que hoy nos desarrollamos conduce a un camino garantista y proteccionista donde la libertad intrínseca corresponde a la propia esencia del ser humano y a su capacidad para decidir libremente, aspecto de una sociedad moderna que configura una preocupación estadual constante e interminada.

Así, debe quedar claro que la libertad implica poder elegir de manera autónoma y sin coacción en las expresiones de cada individuo. En ese sentido, la libertad de los individuos se extiende al pensamiento, la decisión y la expresión de las ideas, resultado de una construcción y materialización razonada que no cause perjuicio en los demás individuos, esto es, autorregulación individual.

Por ello, la coexistencia entre pensamiento y expresión es de gran relevancia y entonces resultaría inútil hablar de pensamientos si no es posible expresarlos, la construcción de ideas y de pensamientos, representa parte fundamental de la libertad de expresión.

Uno de los principios fundamentales que también brindan base a la libertad de expresión es que nunca debe aceptarse una información o limitación legal a la expresión como completamente cierta o idónea, la veracidad de la información es discutible y el individuo tiene derecho a una pluralidad de información para poder tener un criterio y opiniones futuras, las cuales no podrán limitar en forma arbitraría.

Hoy, los derechos se encuentran por encima del poder político y constituyen el fundamento de legitimación del poder, siendo los individuos quienes en ejercicio de sus libertades, pueden emitir sus opiniones, expresarse res- 
pecto de la actividad de sus gobernantes, sin repercusión alguna, y solicitar el reconocimiento y garantía de sus derechos.

Ninguno de los autores mencionados en este artículo, cuestionan la base de la libertad de expresión en la libre manifestación de las ideas. Ninguno acepta que los pensamientos no puedan ser dados a conocer. Ningún filósofo contemporáneo releva a las autoridades de su responsabilidad de evitar cualquier restricción innecesaria a la participación efectiva del individuo en armonía con sus necesidades.

En ese sentido, concluimos en que la información y el acceso a las ideas vienen a constituir el punto de partida en la libertad de expresión, por lo que corresponde al Estado su procuración. Es cierto que, en la mayoría de los casos, los derechos no se respetan y menos aún si de libertad de expresión se habla, pero corresponde al gobierno evitar el silencio de la mayoría de los individuos.

Por eso nuestra propuesta estriba en la protección y no restricción de los derechos humanos por parte del Estado democrático, esto es, una limitación al arbitrio arbitrario de la nación mediante tipos penales o sanciones administrativas contrarias a la libertad de expresión, el principio de igualdad y la propia democracia.

Muchas veces los individuos, por propia voluntad, acatan de manera tajante los mandamientos de la autoridad pero, tratándose de libertad de expresión, el campo debe quedar abierto a la duda. Habrá cuestiones que para el gobernante no serán tan cómodas y tratarán que dicha cuestión no se haga más extensa ni llegue a más oídos o inclusive, sin obrar de mala fe, puede suceder que la autoridad caiga en un error y silencie algo que es totalmente verdadero.

De ahí la importancia especial que debe darse a la falibilidad de la autoridad y el silenciamiento de la verdad por el error, pues todo lo humano es susceptible de inexactitud.

En ocasiones sucede que el individuo tiene la intención de decir algo, pero sabe que al decirlo implicaría ser sancionado por parte de su gobernante. Sabe que lo que desea expresar es algo que puede beneficiar a sus iguales, pero también que puede perjudicar a los que gobiernan y sabe que, de forma indirecta, su libertad está limitada, pues se considera que tuvo total acceso a las fuentes de información, tanto públicas como privadas, que trabajó en su idea, la analizó, la debatió, llegó a una conclusión y ahora su pensamiento está completo, ha llegado el momento de 
expresarlo y hacer que todos lo sepan pero puede detenerse porque piensa que habrá consecuencias.

Por eso, resulta indispensable que aquellos que van a decidir conozcan la baraja de opciones y sean capaces de adoptar la mejor decisión de acuerdo a las propuestas y alternativas que se les presentan y claro, sepan elegir las que mayor beneficio les pueda traer. ${ }^{59}$

Ocultar información, limitar su difusión o restringir el acceso a ella por cualquier cuestión, son violaciones graves al derecho a la libertad de expresión, pues, indirectamente, se está causando un agravio al individuo, toda vez que no se le permite informarse, conocer, asimilar y compartir la información a la que, por principio de cuentas, tiene derecho, dejándolo a ciegas y en un plano de ignorancia tal que resulta demasiado complicado, si no es que imposible, que pueda tener conocimiento suficiente sobre las situaciones que le atañen para poder entrar en campos de discusión y plantear un punto de opinión crítico y personal.

\section{BIBLIOGRAFÍA}

ARISTÓTELES, Éthica Nicomachea, trad. de W. D. Ross, Oxford University Press, London, 1925.

— L La política, trad. de Pallí Bonet, Julio, Bruger, España, 1974.

BobBio, Norberto, Liberalismo y democracia, México, Fondo de Cultura Económica, 1996.

CARPIZO, Enrique, Derechos fundamentales interpretación constitucional la corte y los derecho, México, Porrúa, 2009.

CARPIZO, Jorge, "La libertad de expresión frente a la no discriminación", Revista de la Facultad de derecho de México, México, t. LIX, núm. 252, julio-diciembre de 2009.

DAHL, Robert, La democracia, una guía para los ciudadanos, Buenos Aires, Taurus, 1999.

VECCHIO, Giorgio del, Filosofía del derecho, traducción a la 4a. ed. México, UTEHA, 1946, t. I.

Diccionario enciclopédico abreviado, 7a. ed., Madid, Espasa-Calpe, 1957.

ENEGAS, Alberto et al., Limites al poder, los papeles antifederalistas, Buenos Aires, Lumiére, 2004.

59 Idem. 
FERRAJOLI, Luigi, Teoría de la democracia, dos perspectivas comparadas, México, Instituto Federal Electoral, 2001.

Frondizi, Risieri, ¿Qué son los valores?, México, Fondo de Cultura Económica, 2004.

GARcía JuRAdO, Roberto, "Poliarquía y democracia", Estudios Filosofía, Historia y Letras, México, número 47, invierno 96-97.

Gran enciclopedia del mundo, 10a. ed., Barcelona, Duran, 1972, t. 12.

GRONDONA, Mario, Los pensadores de la libertad, Buenos Aires, Editorial Sudamericana, 1986.

HABERMAS, Jürgen, La reconstrucción del materialismo histórico, 5a ed., Madrid, Taurus, 1992.

HobBes, Thomas, Leviatán o la materia, forma y poder de una república eclesiástica y civil, 2a. ed., trad. de Manual Sánchez Sarto, México, Fondo de Cultura Económica, 1980.

Ingenieros, José, El hombre mediocre, México, Grupo Editorial Tomo, 2004.

KANT, Emmanuel, La filosofía como sistema, primera introducción a la crítica del juicio, trad. de Pedro Von Haselberg, Buenos Aires, Facultad de Filosofía y Letras, 1948.

—, La paz perpetua, Buenos Aires, Araujo, 1765.

Legaz y LaCAmBra, Luis, Filosofía del derecho, Michigan, Bosch, 1953.

LOCKE, John, Escritos sobre la tolerancia, edición de Luis Prieto Sanchís y Jerónimo Betegón Carrillo, Madrid, 1999.

MERRYMAn, John, La tradición jurídica romano-canónica, México, Fondo de Cultura Económica, 2004.

Montanelli, Indro, Historia de Roma, Barcelona, DeBolsillo, 2003.

Moro, Tomás, Utopía, Buenos Aires, trad. de Claudio Roquette de Fonvielle, Sopena Argentina, 1941.

RADBRUCH, Gustav, Introducción a la filosofia del derecho, México, Fondo de Cultura Económica, 2005.

RAWLS, John, Liberalismo Político, trad. de Sergio René Madero Báez, México, Fondo de Cultura Económica, 1993.

, Teoría de la Justicia, trad. de María Dolores González, México, Fondo de Cultura Económica, 1978.

Rivera CAStro, Fabiola, “El Imperativo Categórico en la Fundamentación de la metafísica de las costumbres", Revista Digital Universitaria, México, Vol. 5, número 11, 10 de diciembre de 1994. 
Salazar Ugarte, Pedro, "El Estado moderno en México", en FiX-ZAMUdiO, Héctor y Valadés, Diego (comps.), Formación y perspectivas del Estado en México, México, Instituto de Investigaciones Jurídicas UNAM, 2010.

, Pedro, La democracia constitucional. Una radiografía teórica, México, Fondo de Cultura Económica-UNAM.

SÁnCHEZ VÁzQUEZ, Adolfo, Ética, México, Grijalbo, 1969.

Santibáñez, María, "El libre albedrío en La Vida es Sueño", Calderón 2000 homenaje a Kurt Reichenberger en su 80 cumpleaños, España, Kurt und Roswhita Reichenberger, 2002, vol. II.

StuART Mill, John, Sobre la libertad, trad. de Josefa Sainz Pulido, Madrid, Aguilar, 1972.

ToCQueVille, Alexis de, La democracia en América, trad. de Marcelo Arroita-Jauregui, Madrid, Guadarrama, 1969.

Touchard, Jean, Historia de las ideas politicas, España, Tecnos, 2006.

VALAdÉS, Diego, Problemas constitucionales del Estado de derecho, México, UNAM, Instituto de Investigaciones Jurídicas, 2002.

Ventura, Adrian, Secreto Periodístico: Garantía Constitucional, México, Instituto de Investigaciones Jurídicas, 2010.

Fecha de recepción: 22 de mayo de 2012.

Fecha de dictamen: 25 de junio de 2012. 